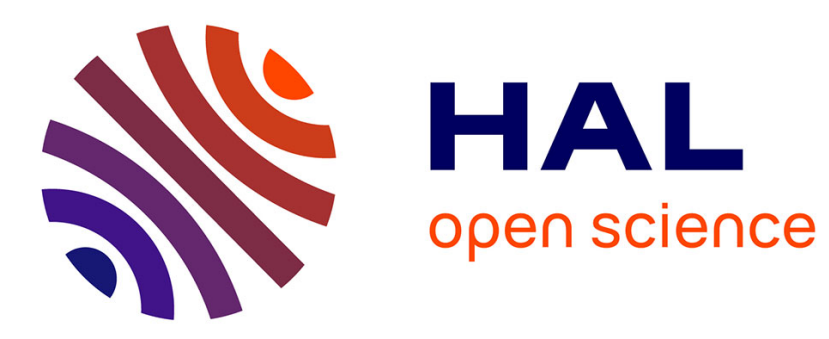

\title{
Design and Integration of an O-band Silicon Nitride AWG for CWDM Applications
}

Sylvain Guerber, Carlos Alonso-Ramos, Diego Perez-Galacho, Xavier Leroux, Nathalie Vulliet, Sébastien Cremer, Delphine Marris-Morini, Frederic Boeuf, Laurent Vivien, Charles Baudot

\section{To cite this version:}

Sylvain Guerber, Carlos Alonso-Ramos, Diego Perez-Galacho, Xavier Leroux, Nathalie Vulliet, et al.. Design and Integration of an O-band Silicon Nitride AWG for CWDM Applications. IEEE 14th International Conference on Group IV Photonics (GFP 2017), Aug 2017, Berlin, Germany. 10.1109/GROUP4.2017.8082232 . hal-02927097

\section{HAL Id: hal-02927097 https://hal.science/hal-02927097}

Submitted on 2 Sep 2020

HAL is a multi-disciplinary open access archive for the deposit and dissemination of scientific research documents, whether they are published or not. The documents may come from teaching and research institutions in France or abroad, or from public or private research centers.
L'archive ouverte pluridisciplinaire HAL, est destinée au dépôt et à la diffusion de documents scientifiques de niveau recherche, publiés ou non, émanant des établissements d'enseignement et de recherche français ou étrangers, des laboratoires publics ou privés. 


\title{
Design and Integration of an O-band Silicon Nitride AWG for CWDM Applications
}

\author{
Sylvain Guerber ${ }^{\mathrm{a}, \mathrm{b}}$, Carlos Alonso-Ramos ${ }^{\mathrm{b}}$, Diego Perez-Galacho ${ }^{\mathrm{b}}$, Xavier Leroux $^{\mathrm{b}}$, Nathalie Vulliet ${ }^{\mathrm{a}}$, Sébastien Crémer ${ }^{\mathrm{a}}$, \\ Delphine Marris-Morini ${ }^{\mathrm{b}}$, Frédéric Boeuf ${ }^{\mathrm{a}}$, Laurent Vivien ${ }^{\mathrm{b}}$, Charles Baudot ${ }^{\mathrm{a}}$, \\ ${ }^{a}$ TR\&D - STMicroelectronics SAS - 850 rue Jean Monnet - 38920 CROLLES FRANCE \\ ${ }^{\mathrm{b}}$ Centre for Nanoscience and Nanotechnology - Bat. 220 - Université Paris Sud - 91405 ORSAY FRANCE \\ sylvain.guerber@st.com
}

\begin{abstract}
Experimental demonstration of an O-band four channel CWDM silicon nitride AWG is reported. Specificity of low order array has been explored through multiple devices among which insertion loss below $2.3 \mathrm{~dB}$, crosstalk level as high as $37 \mathrm{~dB}$ and polarization insensitive flat spectral response is obtained.
\end{abstract}

Keywords - Arrayed Waveguide Grating; Silicon Nitride; Coarse Wavelength Division Multiplexing; Photonics

\section{INTRODUCTION}

Silicon photonics technology provides unreached data densities and integration level while taking benefits from low cost and industrial manufacturing infrastructure of CMOS electronics ${ }^{1}$. This is of particular interest for the implementation of Coarse Wavelength Division Multiplexing (CWDM), which enables transmission of multiple high speed data channel onto a single fibre with low-cost uncooled lasers.

However, the relatively high propagation losses, temperature dependence and roughness-induced phase error of silicon makes it not relevant to implement the multiplexer/demultiplexer (MUX/DEMUX) function. In recent years another common CMOS material, silicon nitride ( $\mathrm{SiN})$, appears as an interesting optical medium ${ }^{2}$. Indeed, $\mathrm{SiN}$ has a thermo-optical coefficient lower than seven times $^{3}$ and its moderate index contrast leads to a more suitable platform for passive devices requiring a good control of the phase, while maintaining a reasonable footprint ${ }^{2}$.

In this paper, the design and experimental demonstration of two O-band four channel CWDM silicon nitride Arrayed Waveguide Grating (AWG) is presented. A first «standard design » is reported as a reference, the second one, «flattened spectral response ", show polarisation insensitive channel flattening.

\section{DESIGN CONSIDERATION}

\section{A. Standard design}

AWG principle has been extensively described in the last decades ${ }^{4,5}$. This AWG was designed in order to fulfil O-band CWDM standard defined by ITU-T, which set channel spacing to $20 \mathrm{~nm}$ and channel centres to $1271,1291,1311 \& 1331 \mathrm{~nm}$. Considering these specifications, the design procedure started from a Free Spectral Range (FSR) higher than $80 \mathrm{~nm}$ to avoid channel overlapping. The FSR can then be linked with the array waveguide order:

$$
m=\frac{n_{e f f W G}\left(\lambda_{c}\right) * \lambda_{c}}{n_{g W G}\left(\lambda_{c}\right) * \lambda_{F S R}}
$$

With $m$ array waveguide order, $\lambda_{c}$ central design wavelength (nm), $n_{\text {effWG }}\left(\lambda_{c}\right)$ array waveguide effective index, $n_{g W G}\left(\lambda_{c}\right)$ array waveguide group index and $\lambda_{F S R}$ free spectral range $(\mathrm{nm})$. This relation set an upper limit to the array order $m$, which leads to the length difference between arrayed waveguide $\Delta L$ :

$$
\Delta L=\frac{\lambda_{c} * m}{n_{e f f W G}\left(\lambda_{c}\right)}
$$

This design procedure is summarised in Fig. 1 (a).

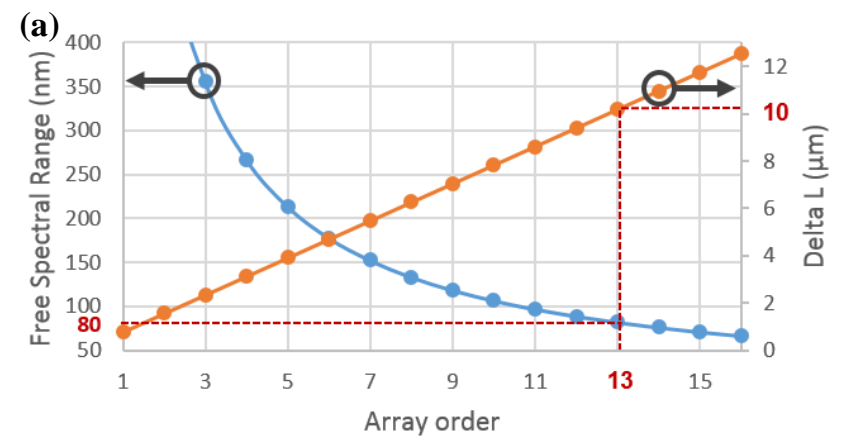

(b)

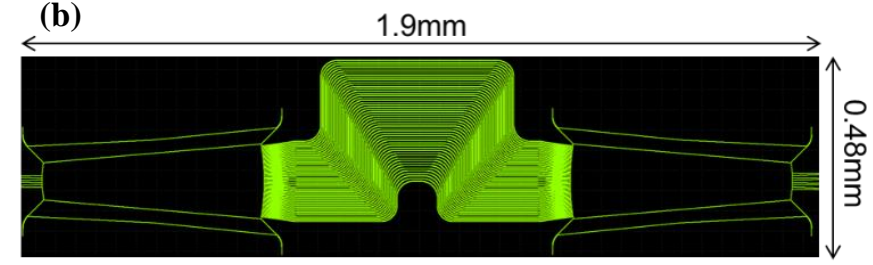

Figure 1: (a) Graphic showing dependence between FSR, array order and array waveguide length difference, (b) AWG layout.

Once the upper limit on $m$ and $\Delta L$ was set, the final values were chosen according other parameters including channel bandwidth, crosstalk level and device footprint. In our configuration, the array order was five, and the number of waveguides in the array 52 .

With such a short $\Delta L$ the usual «U-shape » is not suitable since it will lead to waveguide overlapping in the array. An interesting alternative is the "S-shape ». Its major drawback, additional delay length, is acceptable due to low propagation 
losses of $\mathrm{SiN}$. In addition, the use of straight waveguides avoid layout grid mismatch which can drive phase errors and thus higher floor crosstalk level. The final AWG footprint is less than $1 \mathrm{~mm}^{2}$ as shown in Fig. 1(b).

\section{B. Flattened spectral response design}

Another condition that must be fulfilled to complain with CWDM standard is a flattened spectral response to ensure constant power level transmission on the whole channel bandwidth. This was achieved using a Multi-Mode Interferometer (MMI) as an input waveguide of the $\mathrm{AWG}^{6}$. Moreover, by choosing an appropriate MMI width ${ }^{7}$, beating length for both transverse electric (TE) and transverse magnetic (TM) polarisations can be equal, leading to polarisation insensitive channel broadening as shown in section III. B.

\section{EXPERIMENTAL DEMONSTRATION}

Both AWG presented in the following parts were fabricated on $300 \mathrm{~mm}$ wafers in ST Crolles, Fr. Fig. 2 presents standard design measurements using grating coupler (GC). As GC only worked for TM polarisation this impose to switch on edge coupling for TE measurements of the flattened spectral response device shown on Fig. 3. The larger channel nonuniformity came from the variation of coupling efficiency at the waveguides facet.

\section{A. Standard design}

Fig. 2 shows the spectral response of the standard AWG design. The central channel losses were between 1.91 to $2.29 \mathrm{~dB}$ giving a channel non-uniformity of $0.38 \mathrm{~dB}$. The crosstalk level was better than $36 \mathrm{~dB}$ for all of the four channels.

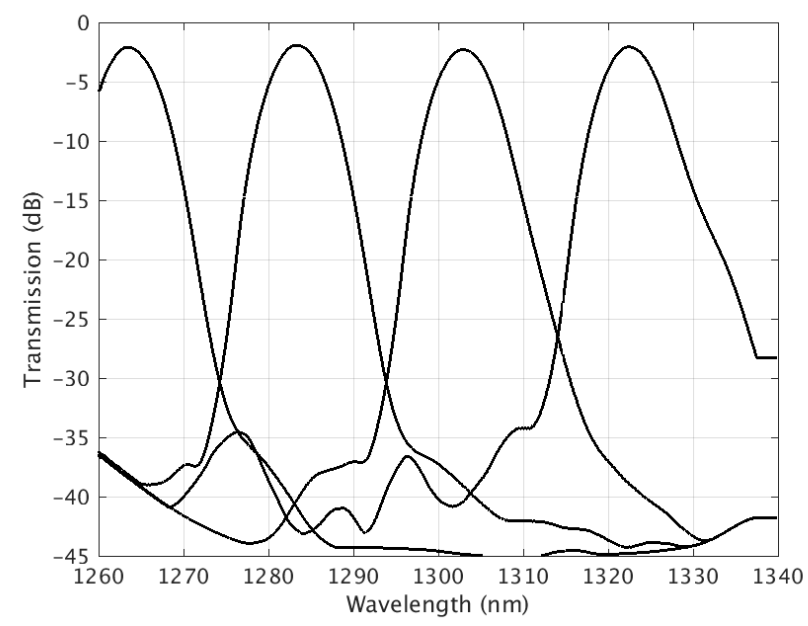

Figure 2: Standard AWG experimental spectral response for TM polarisation. (Characterisation by grating coupler.)

Individual channel shape shown on Fig. 2 were slightly asymmetric. This small widening at the right part of the channel came from residual TE polarisation that was not correctly filtered during measurements.

\section{B. Flattened spectral response design}

As mentioned in section II. B, CWDM standard requires a constant power level transmission on the whole channel bandwidth, which have to fall from 8 to $13 \mathrm{~nm}$. This has been demonstrated experimentally as shown on Fig.3. Both polarisations show the same loss level and the $1 \mathrm{~dB}$ channel bandwidth was $9.2 \mathrm{~nm}$ for TE and $9 \mathrm{~nm}$ for TM demonstrating polarisation independent flattening.

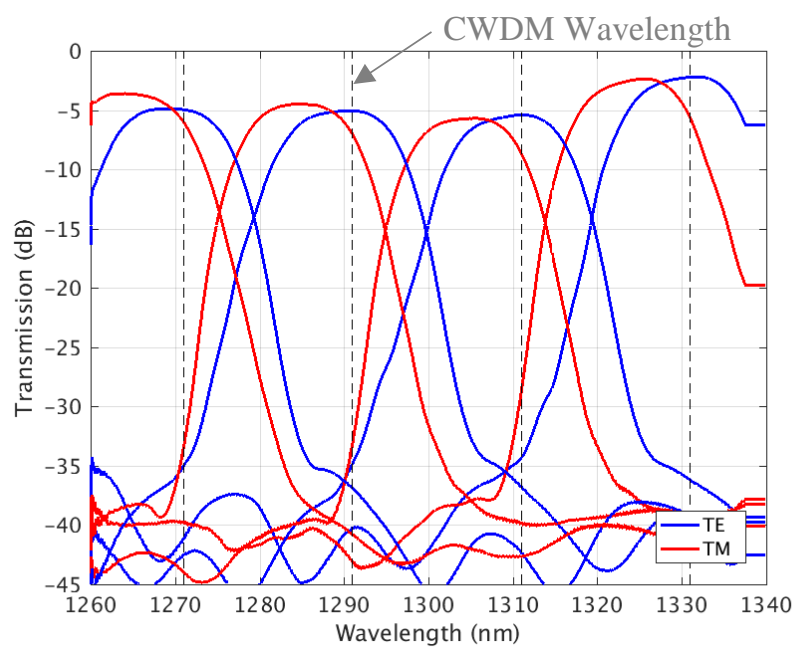

Figure 3: AWG experimental spectral response for TE and TM polarisation. (Characterisation by edge coupling.)

\section{CONCLUSION}

O-band four channel CWDM SiN AWG have been designed, fabricated and characterised. Polarization insensitive channel flattening have been demonstrated with appropriate MMI design. Future work will be focused on spectral polarisation dependence reduction, temperature sensitivity measurements and statistical characterisation for integration in ST 300mm photonic platform.

\section{ACKNOWLEDEMENTS}

This work was partially funded by DGE Nano2017 program and by the European Research Council (ERC) under the European Union's Horizon 2020 research and innovation program (ERC POPSTAR - grant agreement No 647342).

We also acknowledge financial support to this work by the European Commission through the H2020-ICT-27-2015 COSMICC project under grant agreement $n^{\circ} 688516$.

\section{REFERENCES}

${ }^{1}$ D. Thomson et al J. Opt. 18073003 (2016)

${ }^{2}$ R. G. F. Baets et al Optical Fiber Conference paper Th3J.1. (2016)

${ }^{3}$ Zhang, Ziyi et al Conf. Group IV Photonics, pp. 193-194 (2014)

${ }^{4}$ Smit, Meint K., and Cor Van Dam. IEEE J. of Selected Topics in Quantum Electronics 2.2, pp.236-250 (1996)

${ }^{5}$ Adar, R., et al J. Lightwave Technol., 11 pp. 212-219 (1993)

${ }^{6}$ Soole, J. B. D., et al IEEE Photonics Tech. Letters 8.10 pp. 1340-1342 (1996)

${ }^{7}$ LE, Trung-Thanh. J. of Engineering Science and Tech. 8.2 pp 120-130 (2013) 